\title{
Size-Selective Sieving for Detecting Teliospores of Tilletia indica in Wheat Seed Samples
}

\author{
G. L. Peterson and M. R. Bonde, USDA-ARS Foreign Disease-Weed Science Research Unit, Fort Detrick, MD \\ 21702; and J. G. Phillips, USDA-ARS, North Atlantic Area, Wyndmoor, PA 19038
}

\begin{abstract}
Peterson, G. L., Bonde, M. R., and Phillips, J. G. 2000. Size-selective sieving for detecting teliospores of Tilletia indica in wheat seed samples. Plant Dis. 84:999-1007.

A method was developed to isolate teliospores of Tilletia indica from infested grain. The technique was evaluated to determine its sensitivity for detection and quantification of teliospores, the time required to conduct an individual test, and its utility for the detection and identification of the pathogen for phytosanitary regulation and seed certification. A seed wash of a 50-g grain sample was washed through $53-\mu \mathrm{m}$ and $20-\mu \mathrm{m}$ pore size nylon screens to remove unwanted debris and to concentrate and isolate teliospores. The material retained in the $20-\mu \mathrm{m}$ screen was suspended for direct microscopic examination or plated on water agar for teliospore germination and identification by polymerase chain reaction (PCR) utilizing two pairs of $T$. indica-specific primers. The reliability of detection for both light microscopy and PCR are $100 \%$ at an infestation of five teliospores per 50-g sample. The proportion of teliospores recovered from grain samples artificially infested with $T$. indica was $0,82,88,81$, and $82 \%$, respectively, at infestation levels of $0,1,2,5$, and 10 teliospores per 50-g wheat sample. Extraction efficiency was comparable to the centrifuge seed-wash method currently used by most seed health laboratories. Sample analysis using size-selective sieving was more than $83 \%$ faster than the standard centrifuge seed wash.
\end{abstract}

Additional keywords: disease survey, seed wash, spore isolation

Tilletia indica Mitra, the causal agent of Karnal bunt of wheat (Triticum aestivum L., T. durum, and Triticale), was first described in 1930 from the vicinity of the town of Karnal, India (26). By 1996, the disease had been reported from Pakistan, Nepal, Iraq, Iran, and Mexico $(3,12,23,33)$. The importation of grain from countries where the pathogen is present into the United States and other concerned countries is subject to strict quarantine regulation (19,29). In March of 1996, after the conclusion of this study, Karnal bunt was reported for the first time in several limited areas of the southwestern United States $(7,34)$.

Before 7 March 1996, the disease had never been reported in the United States

\section{Corresponding author: Gary L. Peterson}

E-mail: peterson@ncifcrf.gov

Mention of a trademark or proprietary product does not constitute a guarantee or warranty of the product by the U.S. Department of Agriculture and does not imply approval to the exclusion of other products that also may be suitable. All research with pathogens was conducted under the appropriate state and federal permits.

Accepted for publication 27 May 2000.

Publication no. D-2000-0718-01R

This article is in the public domain and not copyrightable. It may be freely reprinted with customary crediting of the source. The American Phytopathological Society, 2000. but was of major concern after numerous interceptions by the U.S. Department of Agriculture (USDA), Animal and Plant Health Inspection Service (APHIS), of infected or contaminated wheat entering the country from Mexico (23). Furthermore, although the initial outbreak of Karnal bunt in Mexico in 1971 was confined primarily to the Yaqui, Fuente, and Mayo valleys in the state of Sonora $(9,33)$, in 1991 it was discovered $300 \mathrm{~km}$ north near Hermosillo. Two years later, the disease was found in isolated fields outside Caborca, Mexico, approximately $80 \mathrm{~km}$ south of the U.S. border (T. Boratynski, APHIS, personal communication). Because of the progressive northern movement of the disease and the international quarantine regulation of this pathogen, we anticipated the potential introduction and establishment of Karnal bunt in the United States would trigger extensive disease surveys, requiring a fast, simple method for detecting teliospores in grain and seed.

In a regulatory climate in which the presence of a single teliospore could lead to regulatory action, the need for a reliable method to detect and identify $T$. indica teliospores in grain could not be overstated. Such a method must meet three requirements: (i) a detection sensitivity approaching one teliospore per 50-g sample; (ii) an extraction time that is quick and cost effective in the evaluation of a large number of samples; and (iii) compatibility with current and developing biochemical and molecular identification methods for $T$. indica $(5,10,15-17,20,24,32)$. The required sensitivity of the technique was dictated by the current "zero tolerance" for $T$. indica teliospores imposed by the United States and several major wheat importing countries. The procedure must enable cost effective processing of numerous samples by a minimum number of personnel in order to facilitate safe and rapid movement of large volumes of wheat with minimal delay. It was predicted that if the pathogen were discovered in the United States, disease surveys would have to be conducted to determine disease distribution, establish regulated areas, and lessen both disease spread and the contamination of conveyances, elevators, and clean export grain. The development of $T$. indica-specific polymerase chain reaction (PCR) primers improved the accuracy of differentiating the pathogen from morphologically similar species (e.g., T. horrida (Takah.) Padwick \& Khan and T. walkeri Castlebury \& Carris) when only a few teliospores are available for evaluation $(15,16,24,32)$. For optimum efficiency, a seed-wash extraction method must be compatible with a PCR assay for detection and identification.

The purpose of this paper is to report the development of a practical technique, referred to as size-selective sieving, for teliospore detection and isolation that meets all the above criteria. The method combines the standard centrifuge seed-wash technique (22) with the use of different size sieves to isolate organisms in a particular size range, a common technique used for extracting fungi from soil $(1,13,18,28)$. Evaluations focused separately on the detection and quantification sensitivities of the extraction method, particularly at infestations of 10 teliospores or less per $50-\mathrm{g}$ sample. The efficacy for both microscopic examination techniques and use in PCR protocols was examined. We compared the efficiency of the method with the standard centrifuge seed-wash method currently in use by most seed-health testing laboratories.

\section{MATERIALS AND METHODS}

Construction of sieves and contamination control in the work environment. Sieves were constructed from two pieces of 7.7-cm-diameter (inside dia.) polyvinyl chloride (PVC) plastic drain pipe, one 38 $\mathrm{mm}$ long and the other $5 \mathrm{~mm}$ long. A $10 \times$ $10 \mathrm{~cm}$ sheet of Spectra Mesh nylon filter 
(Spectrum, Los Angeles, CA) of 20- or 53$\mu \mathrm{m}$ pore size was sandwiched between these two rings and glued together with PVC pipe cement (Fig. 1).

To prevent the accidental transfer of teliospores between samples via residual teliospore contamination on equipment, all glassware was washed thoroughly with warm soapy water, rinsed, soaked in a 1:3 dilution of laundry bleach $(1.6 \%$ active $\mathrm{NaOCl}$ ) for $15 \mathrm{~min}$, rinsed with water, and the openings covered with aluminum foil. Glassware, microscope slides, and disposables were stored away from the extraction area to prevent possible contamination with teliospores. Sieves were washed thoroughly with warm soapy water, rinsed with water, and soaked $15 \mathrm{~min}$ in $1.6 \%$ active $\mathrm{NaOCl}$ solution, rinsed with water, and stored covered. The $\mathrm{NaOCl}$ soak kills residual teliospores and renders them colorless, thus distinguishing them in the event they were accidentally carried into the extraction of the next sample. To maximize the life span of the sieves, chlorination time was rigorously followed and sieves were thoroughly rinsed afterward. An uncontaminated wheat sample (negative control) is processed parallel to the test sample(s) to detect possible cross contamination. All work areas were wiped with a detergent solution before and between processing samples. Research with viable teliospores was conducted in the USDA Agricultural Research Service (ARS), Foreign DiseaseWeed Science Research Unit (FDWSRU), Plant Disease BL3-P Containment Facility $(14,25)$ at Fort Detrick, MD, under federal and state permits.

Protocol for the seed-wash extraction of teliospores from grain by size-selective sieving. The initial steps are similar to

\section{Sieve Construction}

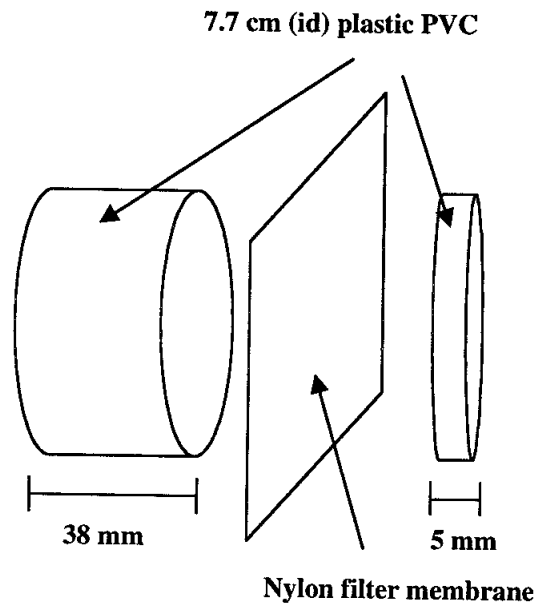

Fig. 1. Components of sieves used for sizeselective sieving were constructed from either 53- or $20-\mu \mathrm{m}$ pore size Spectra Mesh nylon filters sandwiched between two pieces of PVC plastic pipe and glued with PVC plastic pipe cement. those of the standard centrifuge seed-wash procedures (22), in which a 50-g grain sample was transferred to a 500-ml Erlenmeyer flask containing $100 \mathrm{ml}$ of water and two drops of Tween 20 (polyoxyethylene sorbitan monolaurate). The contents were immediately shaken and swirled by hand or on an orbital shaker (200 RPM) for 3 min to release teliospores from the grain. Departing from the centrifuge seed wash protocols, the contents of the flask were poured into a $53-\mu \mathrm{m}$ mesh sieve placed over a 600-ml beaker. The grain deposited on the screen was rinsed twice with $100 \mathrm{ml}$ of water that was first used to rinse the flask. The solution in the beaker was poured through a $20-\mu \mathrm{m}$ mesh screen sieve, and the debris deposited on the screen was rinsed twice with $100 \mathrm{ml}$ of water that was first used to rinse the beaker. The sieve was tilted at 30 degrees, and the teliosporecontaining debris remaining on the $20-\mu \mathrm{m}$ screen and inside walls of the sieve was rinsed to the low side of the sieve with a stream of water from an aspirator bottle, then into a 50-ml beaker using approximately $10 \mathrm{ml}$ of water, and transferred to a 15-ml conical centrifuge tube. The beaker was rinsed with an additional 5-ml of water which was added to the centrifuge tube. The suspended debris was pelleted by centrifugation at $200 \times g$ for $3 \mathrm{~min}$. The pellet was resuspended in $1.0 \mathrm{ml}$ of Shear's mounting medium (8), centrifuged, and depending on pellet volume, resuspended in 30 to $100 \mu \mathrm{l}$ of mounting medium. The entire suspension was transferred to one or more microscope slides, and $22 \times 50 \mathrm{~mm}$ coverslips were applied. The edges of the coverslips were sealed with clear nail polish, and slides were scanned for the presence of teliospores at $\times 100$ magnification.

Evaluation of $20-\mu \mathrm{m}$ pore size sieve for extraction of teliospores. To verify the suitability of the $20-\mu \mathrm{m}$ mesh screen for trapping $T$. indica teliospores, the number and viability of teliospores that passed through the screen were measured. Three collections of infected wheat (MX-91, PAK-87, and IND-91) were used make three separate test samples, each test consisting of 25 bunted seeds from one of the collections. The bunted seeds were shaken in $50 \mathrm{ml}$ of water and Tween 20 to suspend the teliospores. Suspensions were poured through the 53- and 20- $\mu \mathrm{m}$ mesh screens as described above. The debris retained on the $20-\mu \mathrm{m}$ screen was rinsed with approximately $20 \mathrm{ml}$ of water from an aspirator bottle, transferred to a centrifuge tube, and the spores pelleted. The material that passed through the $20-\mu \mathrm{m}$ mesh screen also was pelleted. Teliospores in each fraction were diluted, and samples from each fraction were plated onto three water agar plates and incubated at $18^{\circ} \mathrm{C}$ with $12 \mathrm{~h}$ of light. Percent germination was determined 14 days after seeding plates, and plates with no germinating teliospores were reexamined at 21 days.
Extraction sensitivity of size-selective sieving using artificially infested export wheat samples. Four wheat lots, each containing natural levels of debris typically found in export samples, were infested with $T$. indica teliospores. One lot (HRW91) was composed of USDA Federal Grain Inspection Service (FGIS) samples of hard red winter wheat collected from U.S. wheat export ships leaving U.S. Gulf of Mexico ports in 1991, two lots (HRS91a and HRS91b) were FGIS samples of hard red spring wheat collected from Pacific Northwest ports in 1991, and a fourth lot (MXSW) was of spring wheat from Mexicali, Mexico, collected in 1995 and obtained by FDWSR under APHIS permit. Uncontaminated wheat was divided into 35 50 -g samples, which were separated into seven groups of five 50 -g samples. To each sample within a group, $0,1,2,5$, or 10 intact teliospores were added by the following method. Two suspensions of $T$. indica teliospores (MX-91 and IND-95) were obtained from two infected seeds from each isolate and diluted 1:500 and 1:1,000 with water. Using a Pasteur pipette, varying amounts of spore suspension were transferred to a clean microscope slide with no coverslip and the number of spores counted by microscopic examination at $\times 100$. Broken or immature teliospores were not counted. Teliospores on the slides containing the desired number $(1,2,5$, or 10$)$ were washed by means of a stream of water from an aspirator bottle into a 50-g grain sample. Infested grain samples were air-dried overnight.

Seed-wash extraction and microscopic detection procedures were performed as previously described. The time required to assay individual slides was recorded. Data were analyzed to evaluate both the quantitative recovery of the method (number of teliospores recovered/infestation level of the sample) and frequency of detection (Was T. indica present?).

The number of multiple samples required to attain a high level of confidence for detection was calculated for infestation levels of one and two teliospores per 50-g sample (SAS Institute, 1987, Version 6, Cary, NC).

To compare the sensitivity of this method of extracting teliospores with a standard centrifuge seed-wash method as described by Matsumoto et al. (22), the procedure described above was replicated seven times using the MX-91 isolate of $T$. indica for both extraction methods. The time required to assay individual slides was recorded. Data from the two procedures were compared using the Bonferroni/Dunn LSD $(P=0.05)$ analysis (Stat View, 1993, Software Version 4.01, Abacus Concepts, Berkeley, CA).

To illustrate the difference between sizeselective sieving and the centrifuge seedwash methods, two subsamples of the same wheat lot were processed using both ex- 
traction methods. The entire pellet from each extraction was suspended in $100 \mu \mathrm{l}$ of Shear's mounting medium, three drops transferred to a microscope slide, and an arbitrary microscopic field $(\times 100)$ photographed.

Use of size-selective sieving with PCR assay protocols. Teliospores were isolated by size-selective sieving as previously described with modification. Debris was concentrated by centrifugation and resuspended in $10 \mathrm{ml}$ of distilled water rather than Shear's mounting medium. Following the teliospore germination procedures of Bonde et al $(5,6)$, the suspension was incubated at $20^{\circ} \mathrm{C}$ overnight to encourage hydration and germination of non-Tilletia species, making them more vulnerable to the chlorination step that followed. The next day, the suspension was centrifuged. The pellet was suspended in $0.525 \%$ $\mathrm{NaOCl}$ and centrifuged immediately at $1,000 \times g$ for $1 \mathrm{~min}$. The $\mathrm{NaOCl}$ solution was quickly decanted, and the pellet was resuspended immediately in sterile distilled water, centrifuged at $200 \times g$ for $5 \mathrm{~min}$, and the previous rinse step repeated. The final pellet was resuspended in $500 \mu \mathrm{l}$ of sterile distilled water. The suspension was plated aseptically onto $2 \%$ water agar (Difco Laboratories, Detroit, MI) with antibiotics (100 mg each of ampicillin and streptomycin sulfate per liter) and spread over the surface by a circular rocking motion. Plates were incubated at $21^{\circ} \mathrm{C}$ with 12 $\mathrm{h}$ light. Ten to 14 days after plates were seeded with the wash debris, small blocks of agar on which germinated teliospores were observed were cut, inverted, and stuck to the lids of petri plates. The lids were placed over the dish bottoms, which contained approximately $5 \mathrm{ml}$ of potato dextrose broth (Difco). After 2 to 3 days, a small mat of mycelia, approximately 0.5 to $1.0 \mathrm{~cm}$ in diameter, formed on the surface of the broth. These were each removed with a dissecting needle, touched to a piece of filter paper to remove excess broth, transferred to $1.8-\mathrm{ml}$ round-bottom cryovials, and frozen at $-80^{\circ} \mathrm{C}$. DNA was extracted and PCR conducted as described by Smith et al. (32) using T. indica-specific primer pair TI17M1 and TI17M2, which amplifies an 825-bp product, and primer pair TI57M1 and TI57M2, which produces a 118-bp product. In addition, primer pair ITS3 and ITS4, which amplifies a 420-bp fragment for all Tilletia species studied, was used to confirm that negative results were not caused by PCR inhibitors or that the DNA was degraded. Products were analyzed on $1.2 \%$ agarose gels in TE buffer (40 mM Tris-acetate, $\mathrm{pH} 8.0,1 \mathrm{mM}$ EDTA) followed by staining with ethidium bromide.

PCR assay of teliospores extracted from artificially infested grain samples. Hard red winter wheat collected from U.S. wheat export ships was divided into 25 50g subsamples that were separated into five groups of five. Each group was infested with teliospores of $T$. indica (MX-91) at either $0,1,2,5$, or 10 teliospores per subsample as previously described, adding the teliospores directly to the bag and allowing the water to evaporate overnight. The seedwash procedure was performed as above. In addition, a suspension (ca. 100 teliospores per $\mu \mathrm{l}$ ) of the MX-91 teliospores used in this study was poured through a 20 $\mu \mathrm{m}$ sieve, and the spores were isolated, chlorinated, and plated on water agar to determine the mean percent germination of the collection. Plates were examined for germination after 10 days, germinated spores were isolated, and the mycelium was collected for DNA extraction and assayed by PCR. Data were analyzed to determine percentage of germinated teliospores recovered from each sample and the frequency of pathogen detection and identification by PCR assay.

The number of multiple samples required to attain a high level of confidence for detection (SAS Institute) was calculated for infestation levels of one and two teliospores per 50-g sample.

Microscopic quantification and detection frequency for teliospores extracted from serial dilution of contaminated wheat. One infected seed, approximately $50 \%$ converted to a sorus, was added to a 1-kg subsample of uninfested hard red winter wheat obtained from a Gulf export ship composite sample. The wheat was mixed by repeatedly subdividing it among three 1,000-ml beakers and recombining it approximately 20 times before removing remnants of the original sorus. The wheat was divided into ten 100-g replicates. Each 100-g lot was divided in half, $50 \mathrm{~g}$ was set aside as the undiluted portion, and the other half used to initiate serial dilutions of $1: 10,1: 100,1: 1,000$, and $1: 10,000$ by adding $10 \mathrm{~g}$ of contaminated wheat from each subsequent dilution to $90 \mathrm{~g}$ of uninfested wheat. Fifty grams of each dilution was assayed from each of the 10 replications. Ten 50-g samples of uninfested wheat were included as controls. Ten samples at the same dilution level were processed simultaneously using an orbital shaker and multiple sieve sets, and the processing time was recorded. Teliospores were extracted as described and quantitated by direct microscopic examination. Numbers of teliospores present in each of the 10 undiluted samples were determined with a hemacytometer. The time required to assay each of the 70 slides was recorded.

Application of size-selective sieving to naturally infested grain samples. The method was applied to naturally contaminated samples infested with $T$. indica or $T$. horrida. Samples infested with $T$. indica included six 1-kg wheat samples collected from local farms in Sonora, Mexico, seven 250-g samples collected from commercial grain elevators in India, and a bag of infested chicken feed from Mexico inter- cepted by APHIS in Calexico, CA. Grain samples infested with $T$. horrida included four 500-g samples of rice collected from four counties of Arkansas, three 250-g samples of wheat from ships in Galveston, Pasadena, and Beaumont, TX, and samples of wheat from several grain storage facilities in the vicinity of Galveston. Additional T. horrida-infested samples were a 500-g sample of wheat from California, a sample of rice (Oryza sativa L.) from the Philippines, and a sample of U.S. brome grass (Bromus sp.) seed obtained from Agriculture Canada. One uncontaminated wheat sample was processed with every five contaminated grain samples as a negative control.

Detection and PCR assay of teliospores extracted from naturally infested grain samples. Teliospores were extracted from two 50-g subsamples from each of the naturally infested grain lots listed in Table 1. One sample from each lot was processed for microscopic observation and the other for teliospore germination on water agar for identification by PCR assay as previously described. One uncontaminated wheat sample was processed after every five contaminated grain samples as a negative control. Germinated teliospores were isolated for DNA extraction and assayed by PCR. A 250-mg sample of debris from the bottom of a contaminated railroad car carrying nonagricultural cargo from Mexico to Calexico was also assayed. The debris was added to $100 \mathrm{ml}$ of Tween 20 water and processed the same as a 50-g grain sample.

\section{RESULTS}

Contamination control in the work environment. No teliospores were detected in any of the negative control samples used in these studies, indicating no cross contamination between samples or from the laboratory.

Evaluation of $20-\mu \mathrm{m}$ pore size sieves for extraction of teliospores. Based on evaluation of 3,000 teliospores of each collection with greater than $20 \mu \mathrm{m}$ diameter, germination of isolates IND-91, PAK87 , and MX-91 was 64,66 , and $67 \%$, respectively, after 14 days. This was in contrast to germination of 0,0 , and $0.001 \%$, respectively, of teliospores less than $20 \mu \mathrm{m}$ diameter examined after 14 and 21 days. The teliospores trapped on the 20$\mu \mathrm{m}$ filter constituted 58,67, and $45 \%$, respectively, of the total spores extracted. The teliospores that passed through the 20$\mu \mathrm{m}$ filter were hyaline to yellow in color with a few light brown spores with undeveloped ornamentation.

Extraction sensitivity of size-selective sieving using artificially infested export wheat samples. In the four experiments, 0 , $82,88,81$, and $82 \%$ of the teliospores were recovered from $50-\mathrm{g}$ wheat samples infested with $0,1,2,5$, and 10 teliospores, respectively (Table 2, experiments 1 to 4 ). 
The frequencies of detecting the presence of $T$. indica teliospores by microscopic examination were $0,0.82,0.93,1.00$, and 1.00 of wheat infested at $0,1,2,5$, and 10 teliospores per 50 -g grain sample, respectively (Table 3 , experiments 1 to 4 ).

Assuming an equal distribution of teliospores, the numbers of wheat samples from a single lot required to increase the level of confidence to $99.9 \%$ for detection of teliospores by microscopic observation at infestation levels of 1 and 2 teliospores per 50 -g sample were 6 and 4 , respectively (Table 4).

In the experiment comparing the sensitivity of the centrifuge seed-wash procedure with size-selective sieving, the percentages of teliospores recovered using the centrifuge seed-wash procedure were 0,71 , 71,64 , and $79 \%$, compared with $0,86,79$,
71 , and $71 \%$ for size-selective sieving of wheat at infestations of $0,1,2,5$, and 10 teliospores per 50-g wheat sample, respectively. No significant differences in detection sensitivity were observed between the two methods using the Bonferroni/Dunn $\operatorname{LSD}(P=0.05)$ analysis.

There were no significant differences in the probability that $T$. indica was detected between samples extracted by the sizeselective sieving and the centrifuge seedwash methods, the latter being equal to 0 , $0.71,1.0,1.0$, and 1.0 at $0,1,2,5$, and 10 teliospores per 50-g sample, respectively (Table 2, experiments 4 to 8).

The observed difference between sizeselective sieving and the centrifuge seedwash methods was in the ease and speed of sample analysis. In Figure 2A, illustrating size-selective sieving, most debris has been eliminated, whereas the quantity and density of debris for the centrifuge seed-wash procedure, illustrated in Figure 2B, made observation, teliospore quantification, and identification difficult and time-consuming.

Use of size-selective sieving with PCR assay protocols. Utilizing size-selective sieving, the percentage of germinated teliospores from four experiments that subsequently were recovered from agar plates and assayed by PCR were $0,45,48,74$, and $63 \%$ from $50 \mathrm{~g}$ of wheat samples infested at $0,1,2,5$, and 10 teliospores per sample, respectively.

The frequency of detecting and identifying individual germinated teliospores of T. indica by PCR assay were $0,0.45,0.55$, 1.00 , and 1.00 for wheat infested at $0,1,2$, 5 , and 10 teliospores per $50-\mathrm{g}$ wheat sam-

Table 1. Detection of Tilletia indica and T. horrida teliospores in naturally infested grain samples by microscopic examination and polymerase chain reaction (PCR) assay of germinated teliospores

\begin{tabular}{|c|c|c|c|c|c|c|c|}
\hline \multirow[b]{2}{*}{ Collection } & \multirow{2}{*}{$\begin{array}{l}\text { No. teliospores } \\
\text { PCR assayed }\end{array}$} & \multirow[b]{2}{*}{ Origin } & \multirow[b]{2}{*}{ Source ${ }^{b}$} & \multirow[b]{2}{*}{ Grain type ${ }^{c}$} & \multicolumn{2}{|c|}{$\begin{array}{c}\text { PCR results }{ }^{\mathrm{a}} \\
\text { T. indica-specific primers } \\
\end{array}$} & \multirow{2}{*}{$\begin{array}{l}\text { No. teliospores } \\
\text { observed }^{\mathrm{d}}\end{array}$} \\
\hline & & & & & TI17M1/2 & TI57M1/2 & \\
\hline \multicolumn{8}{|l|}{ T. indica } \\
\hline MX88 & 3 & Mexico 1988 & 1 & W & + & + & TNTC $^{\mathrm{e}}$ \\
\hline MX87 & 1 & Mexico 1987 & 1 & W & + & + & TNTC \\
\hline Calexico CF & 5 & 1986 Calif. intercept $\mathrm{f}^{\mathrm{f}}$ & 2 & $\mathrm{~W}$ & + & + & TNTC \\
\hline Mexicali RR & 1 & 1986 Calif. boxcar ${ }^{f}$ & 2 & $\mathrm{D}$ & + & + & 8 \\
\hline MV-86 & 3 & Mexico 1986 & 1 & W & + & + & 1,227 \\
\hline S-9 & 3 & Mexico 1993 & 1 & W & + & + & 83 \\
\hline S-6210 & 4 & Mexico 1993 & 1 & W & + & + & 115 \\
\hline S-6197 & 4 & Mexico 1993 & 1 & W & + & + & 48 \\
\hline S-205 & 3 & Mexico 1993 & 1 & W & + & + & 12 \\
\hline HD-2324 & 3 & India 1995 & 3 & $\mathrm{~W}$ & + & + & 2,205 \\
\hline WH-342 & 3 & India 1995 & 3 & W & + & + & 3,639 \\
\hline JA 2329A & 3 & India 1995 & 3 & W & + & + & 6,390 \\
\hline MD 2329A & 3 & India 1995 & 3 & W & + & + & 3,998 \\
\hline MD 2329B & 3 & India 1995 & 3 & W & + & + & 2,371 \\
\hline MD 2329C & 3 & India 1995 & 3 & W & + & + & TNTC \\
\hline COAN 3004 & 3 & India 1995 & 3 & W & + & + & TNTC \\
\hline \multicolumn{8}{|l|}{ T. horrida } \\
\hline Loudon Co. & 1 & Loudon Co., AK 1994 & 5 & $\mathrm{R}$ & - & - & 847 \\
\hline Miss. Co. & 2 & Miss. Co., AK 1994 & 5 & $\mathrm{R}$ & - & - & 2,014 \\
\hline Cross Co. & 2 & Cross Co., AK 1994 & 5 & $\mathrm{R}$ & - & - & 1,334 \\
\hline AK Co. & 1 & Arkansas Co., AK 1994 & 5 & $\mathrm{R}$ & - & - & 2,756 \\
\hline Wash. & 1 & Washington 1985 & 6 & $\mathrm{~W}$ & - & - & 182 \\
\hline Glen Co. & 3 & Glen Co., CA 1985 & 7 & W & - & - & 16 \\
\hline Philip. & 7 & Philippines 1989 & 8 & $\mathrm{R}$ & - & - & 33 \\
\hline TM-6C & 1 & Galveston, TX 1991 & 7 & W & - & - & 4 \\
\hline $55457 \mathrm{Fa}$ & 1 & Beaumont, TX 1991 & 4 & W & - & - & 27 \\
\hline Tb TX 1991 & 1 & Galveston, TX 1991 & 4 & $\mathrm{~W}$ & - & - & 63 \\
\hline $55486 \mathrm{~L}$ & 1 & Beaumont, TX 1991 & 4 & W & - & - & 13 \\
\hline 63335 & 1 & Galveston, TX 1991 & 4 & W & - & - & 8 \\
\hline $63212 \mathrm{~F}$ & 1 & Galveston, TX 1991 & 4 & W & - & - & 4 \\
\hline $55457 \mathrm{~F}-\mathrm{T} 1$ & 1 & Beaumont, TX 1991 & 4 & W & - & - & 17 \\
\hline R-1 TX Comp & 1 & Galveston, TX 1991 & 7 & $\mathrm{R}$ & - & - & 54 \\
\hline Sl-GA & 5 & Galveston, TX 1991 & 9 & W & - & - & 372 \\
\hline CAN-Brom ${ }^{\mathrm{g}}$ & 2 & Vancouver, Canada & 10 & B & - & - & 115 \\
\hline
\end{tabular}

${ }^{\mathrm{a}}+=825-$ and 118 -bp products amplified using primer pairs TI1Mi/M2 and TI57M1/M2, respectively. All teliospore DNA produced a 420-bp product when amplified using primers ITS3/4. - = no DNA amplified using primer pairs TI1Mi/M2 and TI57M1/M2. All teliospore DNA produced a 420-bp product when amplified using primers ITS3/4.

b 1 = G. Fuentes-Davila, CIMMYT, Mexico; 2 = T. Boratynski, APHIS, PPQ, El Centro, Ca; 3 = H. S. Dhaliwal, Punjab Agric. Univ., Ludhiana, India; $4=$ G. Peterson, USDA, ARS, Frederick, MD; 5 = F. Lee, Univ. of Arkansas, AK; $6=$ R. Kahn, USDA, APHIS, Hyattsville, MD; $7=$ T. Matsumoto, Calif. Dept. of Agric., Sacramento; 8 = J. Bonman, International Rice Institute, Manila, Philippines; 9 = G. Urskin, USDA, Federal Grain Inspection Service, Galveston, TX; $10=$ G. White, Plant Protection and Quarantine, Agriculture Canada, Ottawa, Canada.

${ }^{\mathrm{c}} \mathrm{W}=$ wheat; $\mathrm{R}=$ rice; $\mathrm{D}=$ railroad car debris; $\mathrm{B}=$ brome grass.

${ }^{\mathrm{d}}$ Number of teliospores recovered by size-selective sieving of a 50-g grain sample from each collection and counted microscopically.

e Too numerous to count (greater than 10,000 teliospores per sample).

${ }^{\mathrm{f}}$ Quarantine interception from Mexico by USDA, Animal and Plant Health Inspection Service (APHIS).

g Brome grass of U.S. origin intercepted by PPQ, Agric. Canada. 
ple, respectively (Table 3 , experiments 5 to 8). The mean germination percentage for the teliospore collection, (MX-91) was $55 \%$ (range 48 to $60 \%$ ) after 10 days of incubation.

Assuming an equal distribution of teliospores, the numbers of wheat samples processed from a single lot required to increase the level of confidence to $99.9 \%$ for detection of teliospores by PCR at infestation levels of 1 and 2 teliospores per 50 -g sample were 16 and 12, respectively (Table 4).

Both methods were equally reliable $(100 \%)$ at detecting the presence of the pathogen when five or more teliospores were present in a 50-g wheat sample. At 1 to 2 teliospores per 50 -g of wheat, the visual detection sensitivity was much greater than for the PCR method (Fig. 3).

Microscopic quantification and detection frequency for teliospores extracted from serial dilutions of contaminated wheat. The infestation level of the undiluted samples was 9,490 teliospores (range 7,500 to 13,500 ) per 50-g sample (Table 5). At 1:10,000 dilution, the detectable infestation level was 0.8 teliospores (range 0 to 2) per 50-g sample.

T. indica teliospores were detected by microscopic examination in all sample dilutions up to and including 1:1,000. At the $1: 10,000$ dilution level, roughly equivalent to the artificial infestation level of 1 teliospore per $50-\mathrm{g}$ sample $(0.82$, SD $0.39)$, the frequency of detection was 0.50 (SD 0.90).

The mean time required to scan an individual slide prepared from a sample pellet derived from size-selective sieving was 3.7 min (range: 2.5 to $5.0 \mathrm{~min}$ ). Although this duration per slide did not differ significantly from those prepared from the centrifuge seed-wash extraction (4.3 $\mathrm{min})$, the number of slides required to examine a single sample was markedly different. Depending on the amount of debris in the sample pellet, the centrifuge seed-wash method required 5 to 12 slides per sample, with an average of 6 . In contrast, $98 \%$ of the sample pellets derived from size-selective sieving required a single slide per sample (range 1 to 2 ).

Application of size-selective sieving to naturally infested samples. Teliospores were successfully recovered from all samples processed for microscopic examination (Table 1). No cross contamination was detected in negative controls. Of the second set of samples processed for PCR assay, germinating teliospores were isolated from all naturally infested grain samples and the railcar debris 8 to 14 days after seeding plates. DNA was extracted as previously described (32). Neither of the $T$. indica-specific primers pairs form a product from T. horrida DNA. All Tilletia isolates tested produced a 420-bp fragment using primer pair ITS3 and ITS4, confirming that negative results were not caused by PCR Representative assay results for four $T$. indica and four T. horrida teliospores are shown in Figure 4A and B, respectively.

\section{DISCUSSION}

It is important to be aware that once a laboratory becomes contaminated with teliospores, the probability of cross contamination of future samples becomes significant, and it is advisable to process a clean wheat sample (control) parallel to the sample(s) being tested. The risk of cross inhibitors or that the DNA was degraded.

contaminating samples excludes the processing of positive wheat extraction controls in the laboratory, since the likelihood of cross contamination is greater than the benefits of including such samples. This does not preclude the use of positive control-specimen microscope slides for maintaining quality control standards in largescale operations where multiple personnel are examining sample slides for the presence or absence of teliospores.

Nylon was chosen for the screen material because it retained a slippery surface,

Table 2. Sensitivity of size-selective sieving for the quantitation of teliospores as determined by microscopic examination and germination of teliospores for polymerase chain reaction (PCR) assays

\begin{tabular}{lccccc}
\hline & \multicolumn{5}{c}{ Number of spores in $\mathbf{5 0}$ g of wheat } \\
\cline { 2 - 6 } Exp./lot $^{\text {a }}$ & $\mathbf{0}$ & $\mathbf{1}$ & $\mathbf{2}$ & $\mathbf{5}$ & $\mathbf{1 0}$ \\
\hline Teliospore recovery & by microscopic observation & \\
1/HRW91 & 0 & $1.00(0)$ & $1.00(0)$ & $0.87(0.23)$ & $0.94(0.11)$ \\
2/HRS91a & 0 & $0.86(0.38)$ & $1.00(0)$ & $0.86(0.15)$ & $0.87(0.11)$ \\
3/HRS91b & 0 & $0.71(0.48)$ & $0.57(0.35)$ & $0.77(0.14)$ & $0.75(0.13)$ \\
4/MXSW & 0 & $0.71(0.48)$ & $0.92(0.19)$ & $0.71(0.16)$ & $0.71(0.09)$ \\
Mean (SD) & 0 & $0.82(0.39)$ & $0.88(0.26)$ & $0.81(0.18)$ & $.082(0.14)$ \\
Quantitative recovery of germinated teliospores ${ }^{\mathrm{c}}$ & & & \\
5/HRW91 & 0 & $0.40(0.55)$ & $0.60(0.55)$ & $0.72(0.11)$ & $0.58(0.15)$ \\
6/HRS91a & 0 & $0.40(0.55)$ & $0.30(0.45)$ & $0.76(0.17)$ & $0.66(0.20)$ \\
7/HRS91b & 0 & $0.20(0.45)$ & $0.30(0.45)$ & $0.880(.27)$ & $0.70(0.10)$ \\
8/MXSW & 0 & $0.80(0.45)$ & $0.70(0.45)$ & $0.60(0.25)$ & $0.56(0.11)$ \\
Mean (SD) & 0 & $0.45(0.51)$ & $0.48(0.47)$ & $0.74(022)$ & $0.63(0.15)$ \\
\hline
\end{tabular}

a Experiments were performed four times, each time with a different wheat lot. Experiments 1 to 4 contained seven replications per treatment, and experiments 5 to 8 contained five replications per treatment. Experiments 1 to 4 and 5 to 8 used wheat lots HRW91, HRS91a, HRS91b, and MXSW, respectively

${ }^{b}$ Ratio of number of teliospores observed in seed wash of all seven treatment-replications to total number of teliospores in the treatment. Mean $=$ combined results of teliospore recovery for all four experiments by treatment to the total number of teliospores in the treatment (standard deviation in parentheses).

c Ratio of total number of germinated teliospores recovered from agar plates for all five replications-treatments, 10 days after seeding with the seed wash, to total number of teliospores in the treatment (standard deviation in parentheses). $\mathrm{P}=$ ratio of total number of germinated teliospores in all four experiments by treatment to the total number of teliospores in the treatment.

Table 3. Sensitivity of size-selective sieving for detecting Tilletia indica using microscopic examination and polymerase chain reaction (PCR) assays

\begin{tabular}{|c|c|c|c|c|c|}
\hline \multirow[b]{2}{*}{ Exp./lot ${ }^{a}$} & \multicolumn{5}{|c|}{ Number of spores in $50 \mathrm{~g}$ of wheat } \\
\hline & $\mathbf{0}$ & 1 & 2 & 5 & 10 \\
\hline \multicolumn{6}{|c|}{ Teliospore detection by microscopic observation ${ }^{b}$} \\
\hline 1/HRW91 & 0 & 1.0 & 1.0 & 1.0 & 1.0 \\
\hline 2/HRS91a & 0 & 0.86 & 1.0 & 1.0 & 1.0 \\
\hline 3/HRS91b & 0 & 0.71 & 0.86 & 1.0 & 1.0 \\
\hline 4/MXSW & 0 & 0.71 & 0.86 & 1.0 & 1.0 \\
\hline Mean (SD) & 0 & $0.82(0.14)$ & $0.93(0.08)$ & 1.0 & 1.0 \\
\hline \multicolumn{6}{|c|}{ Teliospore detection by germination for $\mathrm{PCR}^{\mathrm{c}}$} \\
\hline 5/ HRW91 & 0 & 0.40 & 0.60 & 1.0 & 1.0 \\
\hline 6/HRS91a & 0 & 0.40 & 0.40 & 1.0 & 1.0 \\
\hline 7/HRS91b & 0 & 0.20 & 0.40 & 1.0 & 1.0 \\
\hline 8/MXSW & 0 & 0.80 & 0.80 & 1.0 & 1.0 \\
\hline Mean (SD) & 0 & $0.45(0.25)$ & $0.55(0.19)$ & 1.0 & 1.0 \\
\hline
\end{tabular}

a Experiments were performed four times, each time with a different wheat lot. Experiments 1 to 4 contained seven replications per treatment, and experiments 5 to 8 contained five replications per treatment. Experiments 1 to 4 and 5 to 8 used wheat lots HRW91, HRS91a, HRS91b, and MXSW, respectively.

${ }^{b}$ Ratio of number of samples in which one or more teliospores were detected in the seed wash to the total number of samples in the treatment-replication. Mean $=$ combined results of teliospore detection for all four experiments by treatment to the total number of samples in the treatment (standard deviation in parentheses).

${ }^{c}$ Ratio of number of samples testing positive for $T$. indica in the PCR assay to the total number of samples in the treatment. $\mathrm{P}=$ ratio of samples from all four experiments by treatment to the total number of samples in the treatment (standard deviation in parentheses). 
as opposed to polyester and stainless steel, which tended to retain spores in the recovery process (G. L. Peterson, personal observation). Additionally, we observed gradual corrosion of the stainless steel screens and decomposition of the lead-based solder used to attach the screen to the frames after repeated treatments with $\mathrm{NaOCl}$. The PVC pipe used to construct the sieves should be deeply engraved on the outside with the pore size of the screen to prevent inadvertent reversal of sieve-size sequence while performing the protocol. Alternatively, constructing sieves using two different colors of PVC pipe is an effective method of differentiating sieve sizes. Although most nylon sieves used at FDWSRU have lasted more than 1 year, under heavy use, sieves should be inspected for tears or deterioration every few weeks.

Table 4. Calculated sample size required for microscopic evaluation and the polymerase chain reaction (PCR) assay to be $99.0,99.9$, and $99.99 \%$ confident of detecting the presence of Tilletia indica teliospores in a sample containing 1 and 2 teliospores per 50-g sample

\begin{tabular}{|c|c|c|c|c|c|}
\hline & \multirow[b]{2}{*}{ Infestation $^{\mathrm{b}}$ level } & \multirow[b]{2}{*}{ Cumulative $^{\mathrm{c}} \%$} & \multicolumn{3}{|c|}{$\begin{array}{c}\text { Sample size required to increase detection } \\
\text { Level of confidence }(\%)\end{array}$} \\
\hline & & & 99.0 & 99.9 & 99.99 \\
\hline \multicolumn{6}{|l|}{ Microscope } \\
\hline & 1 & 82 & 3 & 5 & 6 \\
\hline & 2 & 93 & 2 & 3 & 4 \\
\hline \multicolumn{6}{|l|}{ PCR assay } \\
\hline & 1 & 45 & 8 & 12 & 16 \\
\hline & 2 & 55 & 6 & 9 & 12 \\
\hline
\end{tabular}

a Number of 50-g samples from a grain lot required for specific levels of confidence for detection assuming independent samples and a binomial distribution.

${ }^{\mathrm{b}}$ Number of teliospores present in a 50-g grain sample.

${ }^{c}$ Based on four experiments, the mean frequency of pathogen detection in a single 50-g sample.
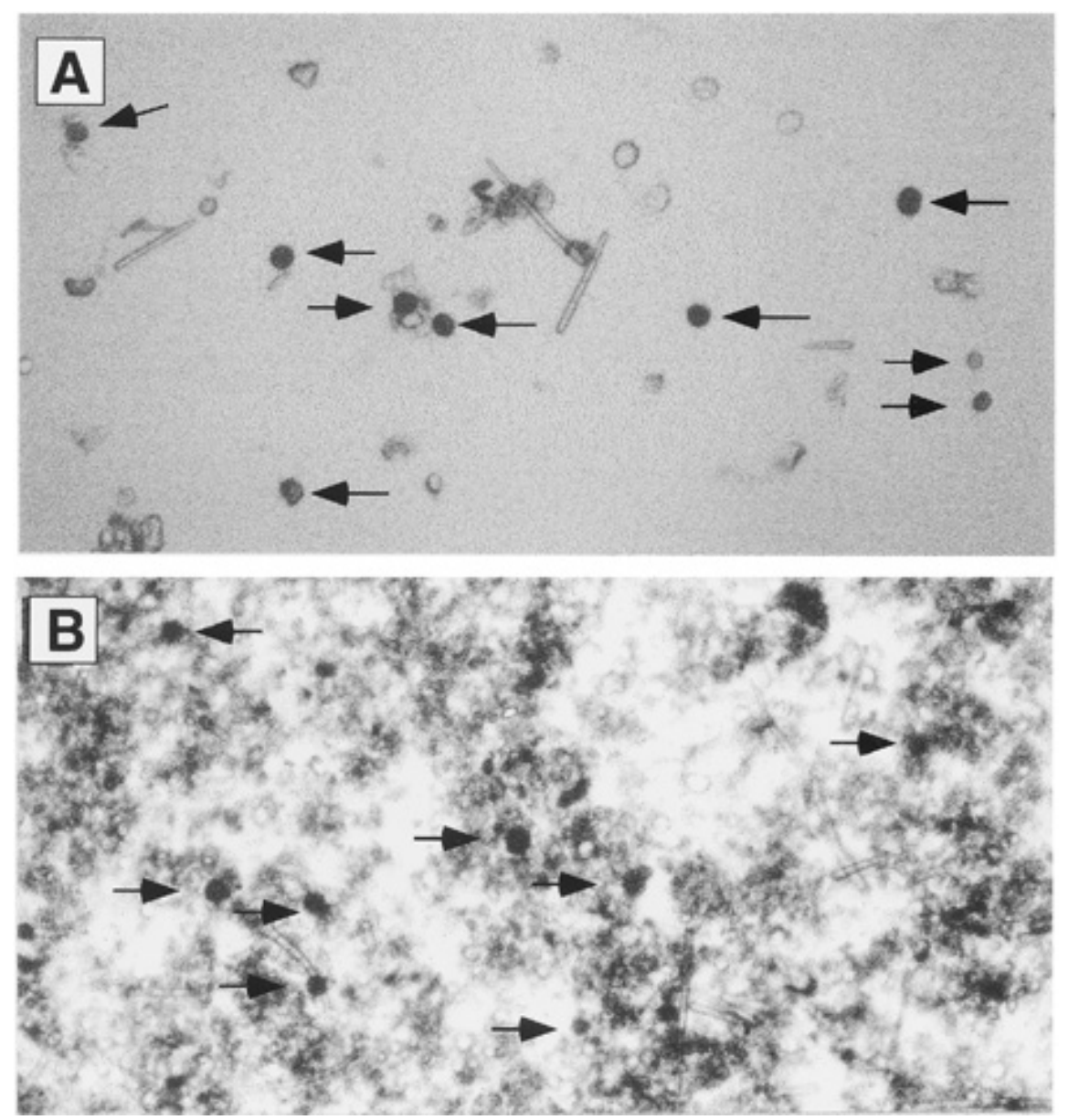

Fig. 2. Microscopic views $(\times 100)$ of two pellets derived from seed-wash extractions of individual 50$\mathrm{g}$ samples taken from a single lot of wheat contaminated with teliospores of Tilletia indica and suspended in $100 \mu \mathrm{l}$ of Shear's mounting medium. (A) Seed-wash extraction using size-selective sieving and (B) a standard centrifuge seed wash. Both slides contain the entire extraction pellet. Arrows denote $T$. indica teliospores.

This method of teliospore isolation is a modification of general centrifuge seedwash assays $(2,3,22)$ currently used by most international seed health laboratories, improved by the incorporation of isolation methods commonly used extracting fungi from soil $(1,13,18,28)$. The use of size-selective sieving allows for a more thorough washing of the grain sample and a final sample pellet containing considerably less debris. Although the actual teliospore recovery by size-selective sieving was not significantly greater than the standard centrifuge seed wash, the reduction of debris greatly decreases the tedium, time, and labor required to process export-ship wheat samples. Grain obtained directly from other sources, such as combines, farm elevators, etc., may contain greater levels of debris than export grain and require additional time to process, but the time would be proportionally less than for the centrifuge seed-wash method. The visual difference in debris levels between size-selective sieving and the centrifuge seed-wash method was illustrated in Figure 2. The dilution of the sample in Figure $2 \mathrm{~B}$, for more accurate detection, would require more than 10 microscope slides and at least $1 \mathrm{~h}$ to examine, whereas Figure 2A using size-selective sieving, most debris has been eliminated and the entire pellet can be examined on a single slide in less than 5 min. The centrifuge seed-wash procedure is reported to require $30 \mathrm{~min}$ for the washing and centrifugation per sample. Based on average time required to examine a slide, and average number of slides produced per sample, each sample would require approximately $1 \mathrm{~h}$ for microscopic examination.

In comparison, teliospore isolation with size-selective sieving takes less than 12

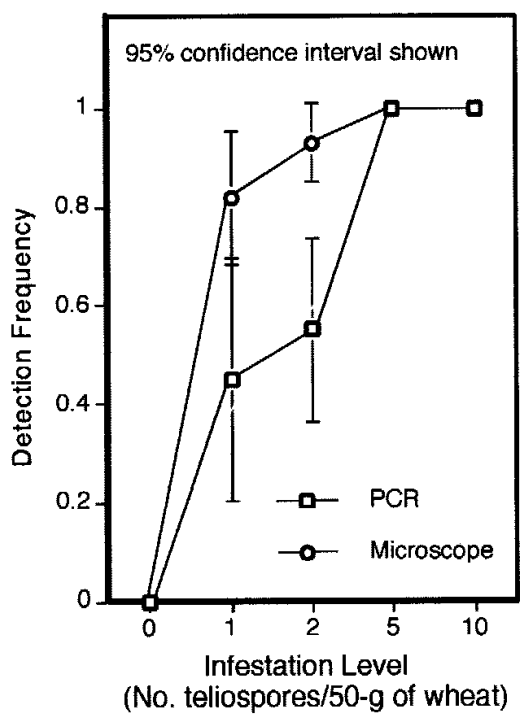

Fig. 3. Comparison of direct microscopic observation and the polymerase chain reaction (PCR) assay for detecting the presence of Tilletia indica teliospores from a seed-wash extraction using size-selective sieving of grain samples artificially infested with teliospores. 
min per sample and less than 5 min to examine microscopically. Utilizing an orbital shaker (200 RPM) for the initial seed wash and multiple sets of sieves, 10 samples can be processed and pelleted in less than 20 min. Microscopic examination of all 10 samples can be completed in $1 \mathrm{~h}$. Results from this study suggested the capability of processing 40 to 50 samples per day by a single experienced individual.

Limitations were found in the practical application of other published extraction methods. The method of Castro et al. (11) filters the seed wash through a $60-\mu \mathrm{m}$ mesh filter, and the sample is collected by vacuum filtration on a $12-\mu \mathrm{m}$ filter. The method is impractical with commercial wheat samples because natural levels of debris clog Millipore filters, necessitating the use of several filters, extensive manipulation, and a final pellet with excessive debris. An attempt to make a direct empirical comparison of this method with this size-selective sieving was abandoned after extraction of the first split-lot sample was incomplete after $4 \mathrm{~h}$, whereas extraction and teliospore quantification was completed in 20 min using size-selective sieving. The glycerol filtration seed assay of Matsumoto et al. (22) traps teliospores and debris on a $20-\mu \mathrm{m}$ mesh filter after removal from a 25-g seed sample in a chromatography column containing a $50 \%$ bubbling glycerol solution. The filters are examined microscopically. The amount of debris, along with filter material, makes it difficult to quantify and/or morphologically evaluate extracted teliospores. Washing debris from the filter and pelleting add additional steps (and time) and do not reduce debris in the sample (K. Kosta, personal communication). These last two methods utilize costly equipment that requires time-consuming and labor-intensive decontamination, cleaning, and maintenance between samples.

In comparison to these other methods, size-selective sieving was very reliable for producing contamination-free teliospores for isolation, germination, and PCR assay. The 53- $\mu \mathrm{m}$ sieve removes most common saprophytes protected in the larger debris that otherwise might escape $\mathrm{NaOCl}$ pretreatment, and the $20-\mu \mathrm{m}$ filter greatly reduces many of the common small-spored ( $<20 \mu \mathrm{m}$ diameter) contaminants, such as Aspergillus and Penicillium. In these studies, only 24 of 723 samples seeded onto water agar plates for germination were contaminated with viable non-Tilletia species, and of these, 19 (2.6\%) contained sufficient contamination to interfere with teliospore isolation for PCR assay.

$T$. indica teliospores can be detected by size-selective sieving at a level of five teliospores per $50 \mathrm{-g}$ sample $100 \%$ of the time. At one to two teliospores per 50-g sample, direct microscopic observation was more reliable for detection. The PCR assay was less sensitive as a detection
Table 5. Number of teliospores extracted from serial dilutions of a 1-kg wheat sample contaminated with one seed infected with Tilletia indica

\begin{tabular}{crcccc}
\hline & \multicolumn{5}{c}{ Dilution } \\
\cline { 2 - 5 } Rep. $^{\mathbf{a}}$ & $\mathbf{1}$ & $\mathbf{1 : 1 0}$ & $\mathbf{1 : 1 0 0}$ & $\mathbf{1 : 1 , 0 0 0}$ & $\mathbf{1 : 1 0 , 0 0 0}$ \\
\hline 1 & 7,500 & 602 & 55 & 6 & 2 \\
2 & 9,300 & 888 & 85 & 3 & 0 \\
3 & 12,300 & 961 & 76 & 6 & 2 \\
4 & 9,300 & 799 & 82 & 8 & 1 \\
5 & 8,500 & 765 & 79 & 7 & 0 \\
6 & 13,500 & 964 & 62 & 9 & 0 \\
7 & 8,500 & 858 & 84 & 5 & 0 \\
8 & 9,500 & 711 & 58 & 8 & 0 \\
9 & 8,500 & 744 & 77 & 7 & 0.8 \\
10 & 8,000 & 615 & 59 & 4 & 0.9 \\
Quantitative recovery & 9,490 & 791 & & & 0 \\
Mean & 1,920 & 129 & 12 & 6 & 0.5 \\
SD & & & & & \\
Detection & 1.0 & 1.0 & 1.0 & 1.0 & 0.9 \\
Freq. & & & & & \\
\hline
\end{tabular}

a A 1-kg sample of wheat was contaminated with teliospores from a single wheat seed infected with T. indica. The $1-\mathrm{kg}$ sample was divided into $10100 \mathrm{-g}$ replications, which were each divided into two 50-g samples. One 50-g wheat sample was extracted to establish an undiluted baseline, and the second 50-g sample was used to make serial dilutions up to 1:10,000. Each sample was extracted by means of size-selective sieving to determine the frequency that $T$. indica was detected by microscopic examination.

\section{$\begin{array}{lllllllllllll}1 & 2 & 3 & 4 & 5 & 6 & 7 & 8 & 9 & 1011 & 121314\end{array}$}
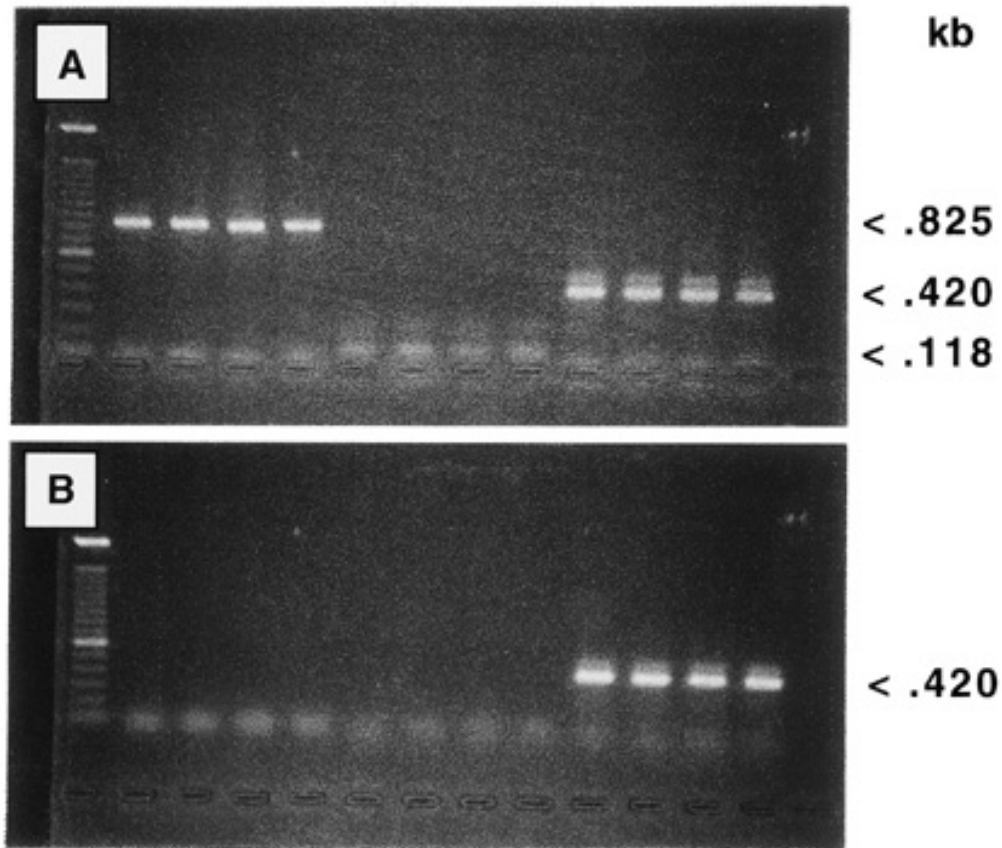

$\begin{array}{lllllllllllll}1 & 2 & 3 & 4 & 5 & 6 & 7 & 8 & 9 & 10 & 111213 & 14\end{array}$

Fig. 4. (A) Agarose gel electrophoresis of polymerase chain reaction (PCR) products from DNA extracted from germinated teliospores of Tilletia indica isolated from a seed wash using size-selective sieving. The repeated order of the four isolates beginning in lane 2 is MX88, Calexico CF, Mexicali RR, and S-9. Lane 1 contains a 100-bp marker, lanes 2 to 5 contain product from the amplification using $T$. indica-specific primers TI17M1 and TI17M2 (825-bp product). Lanes 6 to 9 contain product from amplification using primer pair TI57M1 and TI57M2 (118-bp product). Lanes 10 to 13 contain product from the same DNAs amplified with primer pair ITS3 and ITS4 (420-bp product). Lane 14 contains a water control. (B) Agarose gel electrophoresis of PCR products from DNA extracted from germinated teliospores of $T$. horrida isolated from a seed-wash assay. The repeated order of the four isolates beginning with lane 2 is Cross Co., AR; Philip Co., AR; Loudon Co., AR; and Glen Co., CA. Lane 1 contains a 100-bp marker, lanes 2 to 5 contain results from the amplification using T. indica-specific primers TI17M1 and TI17M2. Lanes 6 to 9 contain results from the amplification using primer pair TI57M1 and TI57M2. Lanes 10 to 13 contain product from the same DNAs amplified with primer pair ITS3 and ITS4 (420-bp product). Lane 14 contains a water control. No product was detected from DNA extracted from germinated T. horrida teliospores and amplified with T. indica-specific primers. 
method only because the current technology requires germinated teliospores. $T$. indica teliospores that are isolated in the seed wash but do not germinate cannot be detected with the current PCR assay. If a PCR or immunochemical assay can be developed that will reliably detect ungerminated teliospores in a seed-wash pellet (23), the sensitivity differences between the two methods may not be significant.

To reliably detect one teliospore of $T$. indica per 50-g sample, multiple samples from each seed lot must be examined. The number of sample replications needed to achieve specific levels of confidence for seed certification based on evaluation of wheat seed composite samples becomes important in an environment of "zero tolerance" when no teliospores are detected in the initial sample assayed.

Although visual microscopic observation is superior to the current PCR assay procedure to detect and quantitate $T$. indica teliospores in grain, a PCR or immunochemical identification procedure would be necessary to differentiate $T$. indica from $T$. horrida or other morphologically similar species. This is particularly important when the number of teliospores is insufficient to make a reliable identification based on morphology, which is often the case. The ability to distinguish teliospores of T. indica from other morphologically similar Tilletia sp. would be critical since other commodities, such as rice, commonly share storage and conveyance facilities, allowing for possible teliospore cross contamination of commodities. In a survey of U.S. wheat export shipments from U.S. Gulf of Mexico ports in 1991 (G. L. Peterson, unpublished data), $8 \%$ of the wheat samples tested contained teliospores of $T$. horrida.

Mathre and Johnson (21), in a study using the centrifuge seed-wash method for detecting T. controversa Kuhn teliospores in grain, postulated that the procedure made it possible to estimate the number of dwarf bunt-infected wheat plants in a field. Extrapolating from the average number of teliospores present in a sorus of $T$. controversa, the total number of teliospores produced in an infected spike was estimated. On the basis of average yield data and the number of teliospores recovered from a seed-wash assay, the total number of infected plants per acre was estimated. In our studies, results from infesting $1 \mathrm{~kg}$ of wheat with a single $T$. indica-infected seed (50\% converted to fungal sorus) suggests that it is possible to detect the presence of a single infected seed in one metric ton of wheat assuming the sorus has ruptured and teliospores are equally distributed throughout the grain. Based on Mathre's reasoning, this would be equivalent to detecting one infected seed in an acre (2.5 infected seeds per ha) of wheat assuming a yield of 2,717 kg/ha.

However, such estimates are not possible for $T$. indica. Unlike $T$. controversa, which infects the host systemically, seeds are not entirely converted to a sorus and all seeds in the spike are not infected. Environmental conditions at the time of infection and cultivar $(4,33)$ affect the production of teliospores in infected seed. Because of these factors, a single infected seed in one wheat spike, under favorable conditions for disease, might produce the same detectable contamination level as 230 infected seeds (or plants) under less favorable conditions.

Although this research has demonstrated the reliability of size-selective sieving in detecting teliospores in a 50-g grain sample, its usefulness as a method of grain certification will be limited by the origin and nature of the sample tested. The variability in the number of teliospores produced by different infected seeds, the randomness of disease distribution in a field, and the variability in the number of teliospores among composite subsamples for a single harvested seed lot limit the potential usefulness of the seed-wash assay for detecting and estimating disease severity at the field level $(27,30,31)$. Research is needed to determine the variability associated with harvest sampling and to develop a reliable composite sampling method. Under the present regulatory climate, such research would be critical to protecting U.S. export markets. Because of the nature of the U.S. national grain handling system, which mixes and combines wheat of similar types and quality from many sources, and utilizes common conveyances on the way to export terminals, the entry of $T$. indica-contaminated grain into the system would lead to regional system contamination and periodically to detectable levels of $T$. indica teliospores in many export shipments. This situation could potentially parallel that of $T$. controversa in the U.S. Pacific Northwest. Although the distribution of $T$. controversa is strictly limited by its environmental requirements to approximately $1 \%$ of the total U.S. winter wheat hectares, teliospores have been found at detectable levels in a significant proportion of U.S. wheat exports from the Pacific Northwest (T. Whitaker, personal communication).

In 1997, during a national disease survey for Karnal bunt, a morphologically similar species, Tilletia walkeri, causing bunt of Lolium sp. was discovered in the Pacific Northwest and Southeast U.S. (10). Lolium (ryegrass) is a common contaminant in wheat and an added component to foragemix seed. The $T$. indica-specific PCR primers used in this study could not differentiate $T$. indica and T. walkeri. Several new pairs of PCR primers have since been developed to differentiate these two species $(16,17)$.

With the discovery of Karnal bunt in the United States, these data and methods related to size-selective sieving were provided to APHIS, ARS, state agricultural departments, and international regulatory agencies. Size-selective sieving was adopted by both the USDA and Agriculture Canada as their official protocol for $T$. indica teliospore detection in grain. The anticipated sensitivity requirements of the method were confirmed in 1996 when greater than $70 \%$ of the field samples testing positive for $T$. indica contained less than 10 teliospores per 50 -g wheat sample, and $46 \%$ contained three or less teliospores (27). To date, size-selective sieving has been used for delimiting the pathogen in Arizona and California, conducting preharvest field surveys, testing of germ plasm, testing of railcar wheat shipments, testing export wheat, conducting a national Karnal bunt survey, PCR identification by APHIS, and in ARS research to isolate teliospores from wheat samples used in research studies.

\section{ACKNOWLEDGMENTS}

We thank Oney Smith, Ray Beck, Jennifer Haines, and Melissa Whitfield, USDA, ARS Foreign Dis.-Weed Sci. Res. Unit (FDWSR) for their technical assistance; Gail Hoover, FDWSR for assistance in manuscript preparation; William L. Bruckart, Richard C. French, Doug G. Luster, Vern D. Damsteegt of FDWSRU; Ed Civerolo, ARS, Davis, CAS; George White, Agric. Canada; Joseph Smilanick, ARS, Fresno, CA; and Roy Gingery, ARS, Nat. Prog. Staff, for their helpful reviews Guillermo Fuentes-Davila, CIMMYT, Mexico; Ted Boratynski, APHIS; Kathleen Kosta and Tim Tidwell of CDFA, for their useful advice and cooperation; H. S. Dhaliwal, Punjab Agric. Univ.; Fleet Lee, Univ. AR; Bob Kahn (retired), APHIS; Tom Matsumoto (deceased), CDFA; Mike Bonman, IRRI; and George Urskin, FGIS for providing contaminated grain; John Pitchford, GIPSA, and Jim Frahm, U.S. Wheat Assoc., for providing wheat from export ships. The continued support and encouragement of Wilda Martinez, Area Director, USDA-ARS-NAA, is gratefully acknowledged.

\section{LITERATURE CITED}

1. Adams, D., Tidwell, T., Ritchey, J., and Wells, H. 1990. Effect of nursery-produced endomycorrhizal inoculum on the growth of redwood seedlings in fumigated soil. USDA For. Serv. Tree Planters' Notes 41:7-11.

2. Agarwal, V. K., Singh, D. V., and Mathur, S. B. 1993. Karnal bunt. Pages 31-43 in: Seedborne Diseases and Seed Health Testing of Wheat. S. B. Mathur and B. M. Cunfer, eds. Jordbrugsforlaget, Fredericksberg, Denmark.

3. Begum, S., and Mathur, S. B. 1989. Karnal bunt and loose smut in wheat seed lots of Pakistan. FAO Plant Prot. Bull. 37:165-173.

4. Bonde, M. R., Peterson, G. L., Fuentes-Davila, G., Aujla, S. S., Nanda, G. S., and Phillips, J. G. 1995. Comparison of the virulence of Tilletia indica, causal agent of Karnal bunt of wheat, from India, Pakistan, and Mexico. Plant Dis. 80:1071-1074.

5. Bonde, M. R., Peterson, G. L., and Matsumoto, T. T. 1989. The use of isozymes to identify teliospores of Tilletia indica. Phytopathology 79:596-599.

6. Bonde, M. R., Peterson, G. L., and Royer, M. H. 1988. Inheritance of isozymes in the smut pathogen Tilletia indica. Phytopathology 78:1276-1279.

7. Bonde, M. R., Peterson, G. L., Smilanick, J. L., and Schaad, N. W. 1997. Karnal bunt of wheat. Plant Dis. 81:1370-1377.

8. Booth, C. 1977. Methods in Microbiology, 
Vol. 4. Academic Press, London.

9. Brennan, J. P., Warham, E. J., Hernandez, J., Byerlee, D., and Coronel, F. 1990. Economic losses from Karnal bunt of wheat in Mexico. CIMMYT Economics Working Paper. Centro Internacional de Mejoramiento de Maiz y Trigo, El Batan, Mexico.

10. Castlebury, L. A., and Carris, L. M. 1999. Tilletia walkeri, a new species on Lolium multiflorum and L. perenne. Mycologia 91:121-131.

11. Castro, C., Schaad, N. W., and Bonde, M. R. 1994. A technique for extracting teliospores from contaminated wheat seeds. Seed Sci. Technol. 22:91-98.

12. Commonwealth Mycological Institute. 1974. Distribution Maps of Plant Diseases, No. 75, 95, 173, and 294, 3rd ed. Commonwealth Agricultural Bureau, Kew, England.

13. Crowe, J. F., Hall, A. S., Greathead, A. S., and Baghott, K. G. 1980. Inoculum density of Sclerotium cepivorum and the incidence of white rot of onion and garlic. Phytopathology 70:64-69.

14. Damsteegt, V. D., Bruckart, W. L., Bonde, M. R., Creager, R. A., Luster, D. G., Yang, S. M., and Schaad, N. W. 1998. Containment research with foreign plant pathogens. Pages 161-165 in: Containment Facilities and Safeguards for Exotic Plant Pathogens and Pests. 1998. R. P. Kahn and S. B. Mathur, eds. American Phytopathological Society, St. Paul, $\mathrm{MN}$.

15. Ferreira, M. A. S. V., Tooley, P. W., Hatziloukas, E., Castro, C., and Schaad, N. W. 1996. Isolation of a species-specific mitochondrial DNA sequence for the identification of Tilletia indica, the Karnal bunt of wheat fungus. Appl. Environ. Microbiol. 62:87-93.

16. Frederick, R. D., Snyder, K. E., Tooley, P. W., Berthier-Schaad, Y., Peterson, G. L., Bonde, M. R., Schaad, N. W., and Knorr, D. A. 1998. An improved PCR method utilizing TaqMan for the detection and differentiation of Tilletia indica, the causal organism of Karnal bunt of wheat, and a related grass smut. (Abstr.) Phytopathology 88:S29.

17. Frederick, R. D., Tooley, P. W., BerthierSchaad, Y., Peterson, G. L., Bonde, M. R., and Schaad, N. W. 1998. Differentiation between, causal organism of Karnal bunt of wheat, and a related ryegrass smut using PCR. 3:3.3.28. Offered Papers Abstracts. International Congress of Plant Pathology, Edinburgh, Scotland.

18. Gerdemann, J. W., and Nicolson, T. H. 1963. Spores of mycorrhizal species extracted from soil by wet sieving and decanting. Trans. Br. Mycol. Soc. 46:235-244.

19. Kahn, R. P., and Hopper, B. 1984. United States and Canadian Quarantine Policies. Karnal Bunt Disease of Wheat-Proceedings of a Conference. Centro Internacional de Maiz y Trigo, Mexico.

20. Luster, D. G., Bonde, M. R., Peterson, G. L., Hack, M. A., and Russo, A. J. 1995. Antibodies recognize a Karnal bunt (Tilletia indica) teliospore wall glycoprotein. (Abstr.) Phytopathology 85:1181.

21. Mathre, D. E., and Johnson, R. H. 1976. Presence of dwarf and common smut in Montana wheat. Plant Dis. Rep. 60:580-583.

22. Matsumoto, T., and Bell, T. 1989. Laboratory guide for the identification of smut fungi of quarantine significance to California. California Department of Food and Agriculture, Sacramento.

23. Matsumoto, T. T., Boratynski, T. N., Showers, D. W., Higuera, D., and Luscher, D. 1984. Karnal bunt of wheat. Calif. Plant Pest Dis. Rep. 3:45-47.

24. McDonald, J. G., Wong, E., Kristjansson, G. T., and White, G. P. 1999. Direct amplification by PCR of DNA from ungerminated teliospores of Tilletia species. Can. J. Plant Pathol. 21:78-80.
25. Melching, J. S., Bromfield, K. R., and King solver, C. H. 1983. The plant pathogen containment facility at Frederick, Maryland. Plant Dis. 67:717-722.

26. Mitra, M. 1931. A new bunt of wheat in India. Ann. Appl. Biol. 8:178-179.

27. Podleckis, E. V., and Firko, M. J. 1998. Karnal bunt: Likelihood spread with proposed 1997 program-plant pest risk assessment. Pages 229-271 in: Proc. Bunts Smuts Wheat: Int. Sympos. North American Plant Protection Organization, Ottawa.

28. Punja, Z. K., Smith, V. L., Campbell, C. L., and Jenkins, S. F. 1985. Sampling and extraction procedures to estimate numbers, spatial pattern, and temporal distribution of sclerotia of Sclerotium rolfsii in soil. Plant Dis. 69:469-474.

29. Royer, M. H., and Rytter, J. 1988. Comparison of host ranges of Tilletia indica and $T$. barclayana. Plant Dis. 72:133-136.

30. Sawyer, A. J. 1997. Detection sampling for teliospores of Tilletia indica (Karnal bunt) and infected kernels in bulk grain. (Abstr.) Phytopathology 87:S85.

31. Sawyer, A. J., Huettel, R. N., and Meyer, R. J. 1997. Within-field spatial distribution of Tilletia indica (Karnal bunt): Implications for detection surveys. (Abstr.) Phytopathology 87:S85.

32. Smith, O. P., Peterson, G. L., Beck, R. J., Schaad, N. W., and Bonde, M. R. 1996. Development of a PCR-based method for identification of Tilletia indica, causal agent of Karnal bunt of wheat. Phytopathology 86:115-122.

33. Warham, E. J. 1986. Karnal bunt disease of wheat: A literature review. Trop. Pest Manage. 32:229-242.

34. Ykema, R. E., Floyd, J. P., Palm, M. E., and Peterson, G. L. 1996. First report of Karnal bunt of wheat in the United States. Plant Dis. 80:1207. 